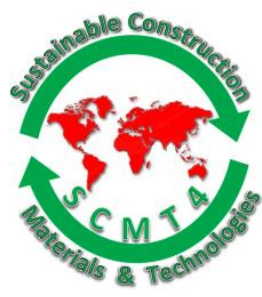

\title{
Evaluation of Preventive Effects of Coating Materials Against Frost Damage in Concrete Based on Outdoor Exposure Test
}

\author{
Takuya Hasegawa $^{1 \mathrm{a}}$, Osamu Senbu ${ }^{1 \mathrm{~b}}$, and Tomoko Fukuyama ${ }^{1 \mathrm{c}}$ \\ Faculty of Engineering, Hokkaido University - Kita 13, Nishi 8, Kita-ku, Sapporo, Hokkaido 060-8628, \\ Japan.1aEmail: <hase-t@eng.hokudai.ac.jp>, ${ }^{1 b}$ Email: <senbu@eng.hokudai.ac.jp>, \\ ${ }^{1 c}$ Email: 〈tmkfkym@eng.hokudai.ac.jp>
}

\begin{abstract}
To make clear the preventive effects of coating materials against frost damage in concrete, accelerated freezing and thawing tests and outdoor exposure tests using concrete specimens with coating materials applied to the surface were conducted. The accelerated test results confirmed the preventive effects of coating materials against frost damage in the concrete. However, it was also observed that deterioration of concrete specimens with a high permeability coating material was accelerated in comparison with uncoated concrete specimens. The outdoor exposure test results also confirmed the preventive effects of coating materials against frost damage in concrete exposed to outdoor conditions. Finally, a method to evaluate the preventive effects of coating materials against frost damage in concrete based on accelerated and outdoor exposure tests is proposed.
\end{abstract}

\section{INTRODUCTION}

Previous studies have reported that organic coating materials have preventive effects against deterioration of reinforced concrete members, such as carbonation and corrosion of reinforcing bars. However, preventive effects of coating materials against frost damage in concrete have not been sufficiently discussed. Some studies have pointed out that the waterproofing properties of coating materials are important for preventive effects [Shirota 1997]. It has also been pointed out frost damage in concrete with some kind of coating material was accelerated in comparison with uncoated concrete. This paper outlines experiments for identifying frost damage preventive effects of coating materials and proposes an approach to estimate the progress of frost damage in coated concrete.

\section{METHODOLOGY OF THIS STUDY}

Table 1 shows the experimental plan of this study. To make clear the frost damage preventive effects of the coating materials, accelerated freezing and thawing tests and outdoor exposure tests were conducted using concrete specimens with coating materials applied to the surface.

The three types of concrete specimens for the accelerated freezing and thawing tests are shown in Table 2. Non-air-entrained (non-AE) concrete was used to avoid the preventive effects of entrained air against frost damage. Four types of coating materials including a high-vapor-permeability coating material were chosen. The coating materials were applied as shown in Table 3 to four sides of the specimen surface after 
two weeks of water curing at $20^{\circ} \mathrm{C}$ and one week of drying at $20^{\circ} \mathrm{C}$. The other two sides of the specimen were sealed by epoxy resin. The coated specimens were subject to an accelerated freezing and thawing test according to JIS A 1148 (ASTM C 666) Procedure A after one month of air curing and two days of water curing. The weight, strain, and frequency of the relative dynamic modulus of elasticity (RDME) were measured during the test.

Two series of outdoor exposure tests as shown in Table 1 were also conducted. The specimens (Table 2) were made in previous studies [Hasegawa 2006, 2008]. Outdoor exposure test 1 considered two types of coating materials. Outdoor exposure test 2 considered six types of coating materials. The properties of the coating materials for outdoor exposure tests 1 and 2 are also shown in Table 3. The coating materials were applied to three sides of the specimens, and an epoxy resin was applied to the other three sides. In outdoor exposure test 2, only the concrete surface facing the ground was uncoated. The exposure site was in Sapporo city (monthly average lowest temperature: $-7.9^{\circ} \mathrm{C}$ ) located in the northern part of Japan. All specimens were placed on a metal mesh rack. Snow that had settled on the specimens during the winter season was not removed. The weight and strain of the specimens were measured after $8 \mathrm{y}$ in outdoor exposure test 1 , and the weight and ultra-sonic propagation velocity were measured after 8.5 and $13 \mathrm{y}$ in outdoor exposure test 2. The RDME was estimated from the measured ultra-sonic velocity using the equation [Sato 2000]

$D F=E_{\mathrm{D}} / E_{\mathrm{D} 0} \times 100$

$E_{\mathrm{D}}=4.0837 V^{2}-14.438 V+20.708$

where $E_{\mathrm{D}}$ is the dynamic modulus of elasticity $\left(\mathrm{N} / \mathrm{mm}^{2}\right), V$ is the ultra-sonic velocity $(\mathrm{km} / \mathrm{s}), D F$ is the $\operatorname{RDME}(\%)$, and $E_{\mathrm{D} 0}$ is the initial value of the dynamic modulus of elasticity $\left(\mathrm{N} / \mathrm{mm}^{2}\right)$; the average value obtained from measurements of sound specimens was taken as $E_{\mathrm{D} 0}$.

The vapor permeability of each coating material was measured using the cup method approved by the Japan Society for Finishings Technology.

Table 1. Experimental Plan of This Study

\begin{tabular}{|l|l|l|l|l|l|}
\hline Series & Test details & $\begin{array}{l}\text { Coating } \\
\text { materials }\end{array}$ & Concrete & $\begin{array}{l}\text { Specimens } \\
(\mathrm{mm})\end{array}$ & $\begin{array}{l}\text { Measurement } \\
\text { items }\end{array}$ \\
\hline $\begin{array}{l}\text { Accelerated } \\
\text { F\&T }\end{array}$ & $\begin{array}{l}\text { Accelerated freezing } \\
\text { and thawing test } \\
\text { (JIS A 1148 } \\
\text { Procedure A) }\end{array}$ & 4 types & $\begin{array}{l}\text { W/C 0.4,0.5 } \\
\text { and } 0.6\end{array}$ & $75 \times 75 \times 400$ & $\begin{array}{l}\text { Weight, strain, } \\
\text { RDME }\end{array}$ \\
\hline $\begin{array}{l}\text { Outdoor } \\
\text { exposure 1 }\end{array}$ & $\begin{array}{l}\text { Outdoor exposure } \\
\text { test (Sapporo city) } \\
8 \text { y }\end{array}$ & 2 types & W/C 0.5 & $75 \times 75 \times 400$ & Weight, strain \\
\hline $\begin{array}{l}\text { Outdoor } \\
\text { exposure 2 }\end{array}$ & $\begin{array}{l}\text { Outdoor exposure } \\
\text { test (Sapporo city) } \\
8.5 \text { and 13y }\end{array}$ & 6 types & W/C 0.575 & $100 \varphi \times 30$ & $\begin{array}{l}\text { Ultrasonic } \\
\text { propagation } \\
\text { velocity }\end{array}$ \\
\hline
\end{tabular}


Table 2. Mix Proportions and Properties of Concrete Used

\begin{tabular}{|c|c|c|c|c|c|c|c|c|c|}
\hline \multirow[t]{2}{*}{ Series } & \multirow[t]{2}{*}{$\mathrm{W} / \mathrm{C}$} & \multirow{2}{*}{$\begin{array}{l}\text { s/a } \\
(\%)\end{array}$} & \multicolumn{4}{|c|}{ Unit weight $\left(\mathrm{kg} / \mathrm{m}^{3}\right)$} & \multirow{2}{*}{$\begin{array}{l}\text { Air } \\
(\%)\end{array}$} & \multirow{2}{*}{$\begin{array}{l}\text { Slump } \\
(\mathrm{cm})\end{array}$} & \multirow{2}{*}{$\begin{array}{l}\text { Strength } \\
\left(\mathrm{N} / \mathrm{mm}^{2}\right)\end{array}$} \\
\hline & & & $\mathrm{W}$ & $\mathrm{C}$ & $\mathrm{S}$ & $\mathrm{G}$ & & & \\
\hline \multirow{3}{*}{ Accelerated $\mathrm{F} \& \mathrm{~T}^{* 1}$} & 0.4 & 47.5 & 185 & 463 & 816 & 920 & 2.1 & 14.5 & 66.6 \\
\hline & 0.5 & 49.7 & 185 & 370 & 892 & 920 & 2.5 & 14.0 & 52.9 \\
\hline & 0.6 & 51.1 & 185 & 308 & 943 & 920 & 2.2 & 19.5 & 40.1 \\
\hline Outdoor exposure $1^{* 1}$ & 0.5 & 44.7 & 185 & 370 & 760 & 960 & 4.3 & 19.0 & 35.1 \\
\hline Outdoor exposure $2^{* 2}$ & 0.575 & 46.2 & 178 & 310 & 820 & 986 & 4.7 & 20.0 & 29.9 \\
\hline
\end{tabular}

*1 Cement: Normal Portland Cement ( $\rho=3.16)$, Coarse Aggregate: Crashed stone $(\rho=2.66)$,

Sand: River Sand $(\rho=2.61)$

*2 Cement: Normal Portland Cement ( $\rho=3.16)$, Coarse Aggregate: Crashed stone ( $\rho=2.70)$,

Sand: River Sand $(\rho=2.59)$

Table 3. Coating Materials Used

\begin{tabular}{|c|c|c|c|c|c|c|}
\hline \multirow[t]{2}{*}{ Series } & \multirow[t]{2}{*}{ Type $^{* 1}$} & \multirow[t]{2}{*}{ Abbreviation } & \multicolumn{3}{|c|}{ Amount $\left(\mathrm{kg} / \mathrm{m}^{2}\right)$} & \multirow{2}{*}{$\begin{array}{c}\text { Vapor Permeability }{ }^{* 2} \\
\left(\mathrm{~g} / \mathrm{m}^{2} \cdot 24 \mathrm{~h}\right)\end{array}$} \\
\hline & & & Base & Main & Top & \\
\hline \multirow[t]{4}{*}{$\begin{array}{l}\text { Accelerated } \\
\text { F\&T }\end{array}$} & $\begin{array}{l}\text { Exterior thin coating } \\
\text { material } \mathrm{E}\end{array}$ & TN-E & 0.20 & 1.20 & - & 41 \\
\hline & $\begin{array}{l}\text { Waterproof exterior } \\
\text { thin coating material E }\end{array}$ & W-TN-E & 0.20 & 1.00 & - & 29 \\
\hline & $\begin{array}{lr}\text { Multi-layer } & \text { coating } \\
\text { material E } & \text { (tp: } \\
\text { acrylic) } & \end{array}$ & ML-E & 0.20 & 1.50 & 0.31 & 34 \\
\hline & $\begin{array}{l}\text { Multi-layer coating } \\
\text { material E (high } \\
\text { vapor permeability } \\
\text { type, tp: acrylic) }\end{array}$ & V-ML-E & 0.20 & 1.50 & 0.31 & 72 \\
\hline \multirow[t]{2}{*}{$\begin{array}{l}\text { Outdoor } \\
\text { exposure } 1\end{array}$} & $\begin{array}{l}\text { Exterior thin coating } \\
\text { material } \mathrm{E}\end{array}$ & TN-E & 0.15 & 1.40 & - & 188 \\
\hline & $\begin{array}{l}\text { Waterproof exterior } \\
\text { thin coating material E }\end{array}$ & W-TN-E & 0.15 & 1.40 & - & 29 \\
\hline \multirow[t]{6}{*}{$\begin{array}{l}\text { Outdoor } \\
\text { exposure } 2\end{array}$} & $\begin{array}{l}\text { Exterior thin coating } \\
\text { material E }\end{array}$ & TN-E & 0.09 & 1.20 & - & 46 \\
\hline & $\begin{array}{l}\text { Exterior thick coating } \\
\text { material E }\end{array}$ & TC-E & 0.09 & 3.25 & - & 74 \\
\hline & $\begin{array}{l}\text { Multi-layer coating } \\
\text { material RE } \\
\text { (tp: urethane) }\end{array}$ & ML-RE-U & 0.15 & 1.35 & 0.30 & 26 \\
\hline & $\begin{array}{l}\text { Multi-layer coating } \\
\text { material RE } \\
\text { (tp: acrylic) }\end{array}$ & ML-RE-A & 0.15 & 1.35 & 0.30 & 65 \\
\hline & $\begin{array}{l}\text { Acrylic resin silicone } \\
\text { paint }\end{array}$ & $\begin{array}{l}\text { Silicone- } \\
\text { Acrylic }\end{array}$ & 0.09 & 0.24 & - & 29 \\
\hline & Fluorine paint & Fluorine & 0.09 & 0.24 & - & 38 \\
\hline
\end{tabular}

*1 tp: top coating, *2 The cup method approved by the Japan Society for Finishings Technology 


\section{RESULTS AND DISCUSSION}

Accelerated freezing and thawing test results. Results of the accelerated freezing and thawing tests are shown in Figure 1. From Figure 1, it was observed that the uncoated W/C 0.4 specimen deteriorated at earlier cycles in comparison with the W/C 0.5 specimen. It seemed that the air content in the concrete affected the results. In general, it was observed that deterioration of coated specimens was delayed in comparison with uncoated specimens. This confirms the preventive effects of coating materials against frost damage in concrete. However, there was more deterioration in the TN-E specimen of W/C 0.5 than in the uncoated specimen at later cycles. According to a previous study [Shirota 1997], deterioration of concrete with a low-waterproof coating material is sometimes accelerated in comparison with uncoated concrete. It seemed that the mass transfer properties of the coating material affected the frost damage in the concrete. From the weight change ratio results in Figure 1, weight change ratios of coated specimens increased in early cycles and decreased in later cycles. In the case of the high-vapor-permeability coating material, the weight change ratio decrease started earlier. It seemed that the high-vapor-permeability coating material was easily deteriorated by the freezing and thawing action. Figure 2 shows the relationship between the RDME and the strain change. At RDMEs higher than $60 \%$, a high correlation between the RDME and strain change was observed. A correlation was not observed for RDMEs of less than $60 \%$. It seemed that concrete specimens with a measured RDME of under $60 \%$ loose elasticity.

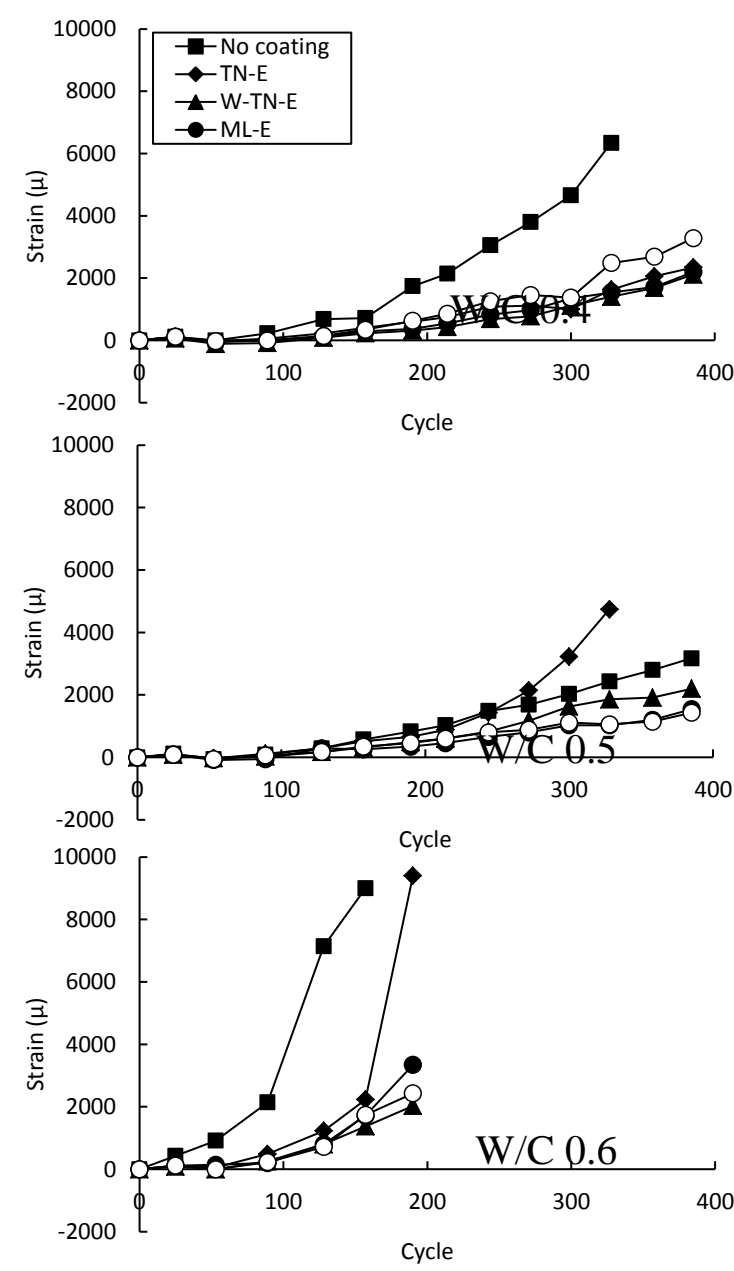

(a) Strain change
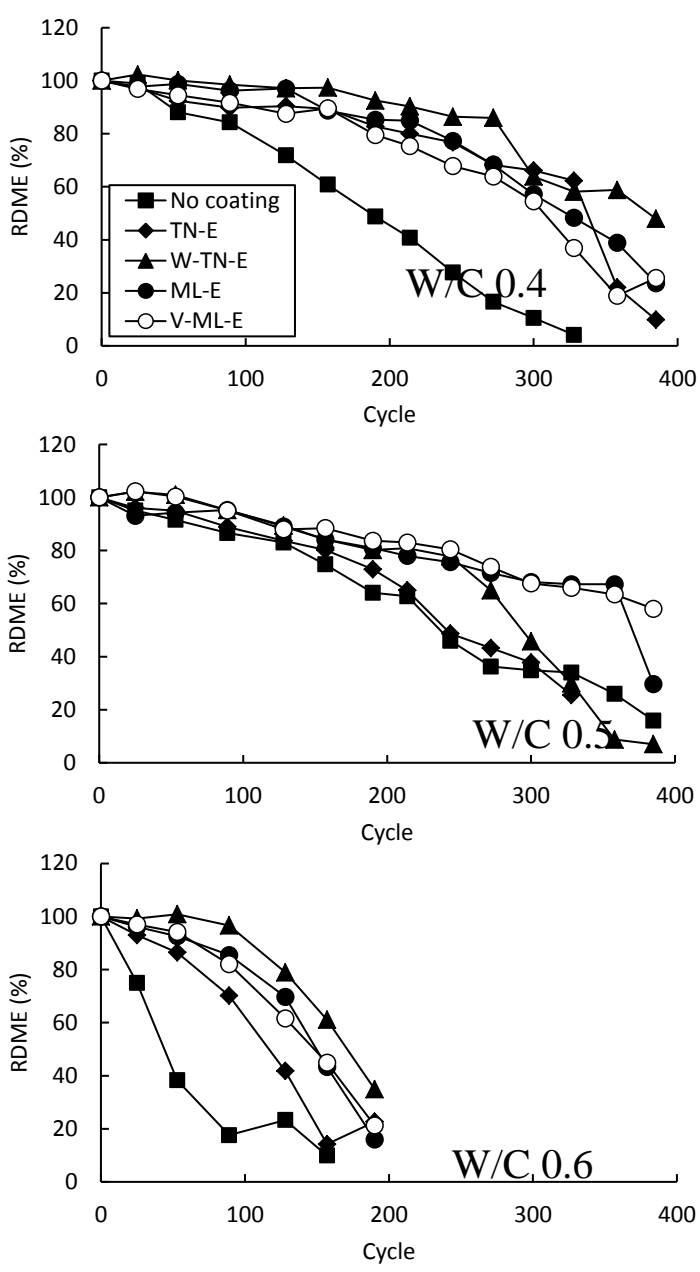

(b) RDME

Figure 1. Results of Accelerated Freezing and Thawing Test (1) 

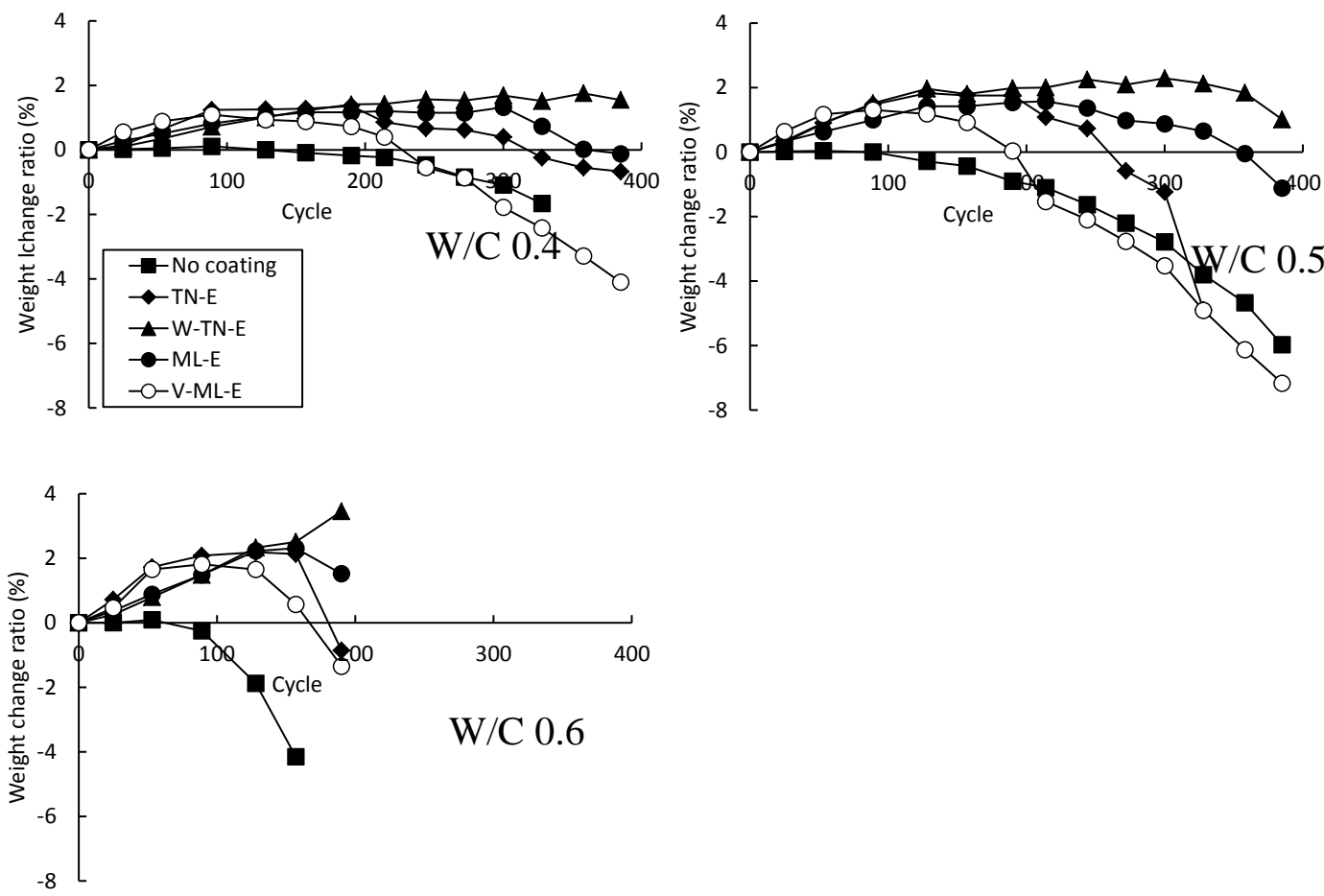

(c) Weight change ratio

Figure 1. Results of Accelerated Freezing and Thawing Test (2)

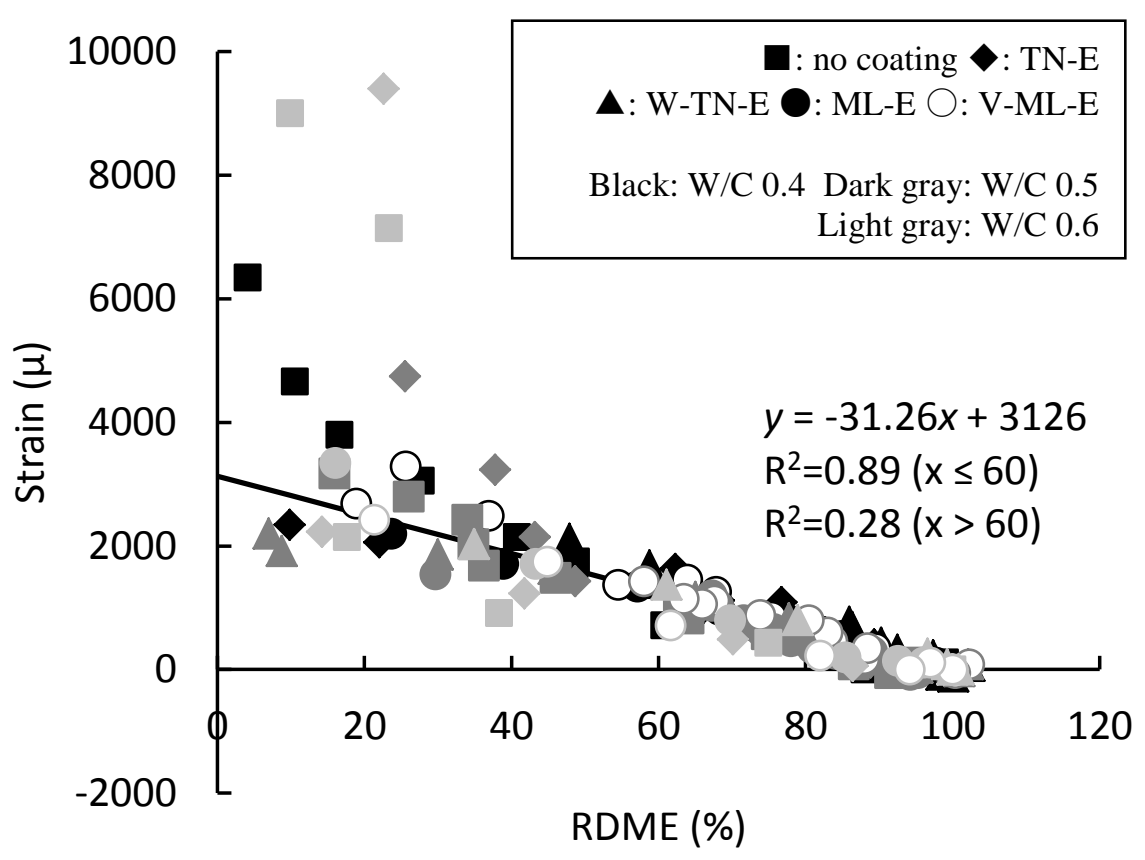

Figure 2. Relationship between RDME and Strain Change 


\section{Method to evaluate the preventive effect of coating material using standardized cycle}

Previous studies have pointed out that the RDME results of JIS A 1148 (ASTM C666 Procedure A) can be standardized regardless of concrete conditions such as the water-cement ratio, air content, and used aggregate [Katsura 2003]. For example, Figure 3 shows the results of the standardization of the uncoated concrete RDMEs. The results were obtained using equation (2).

Standardized cycle $=$ measured cycle $\times 300 /$ the cycle of $60 \%$ RDME

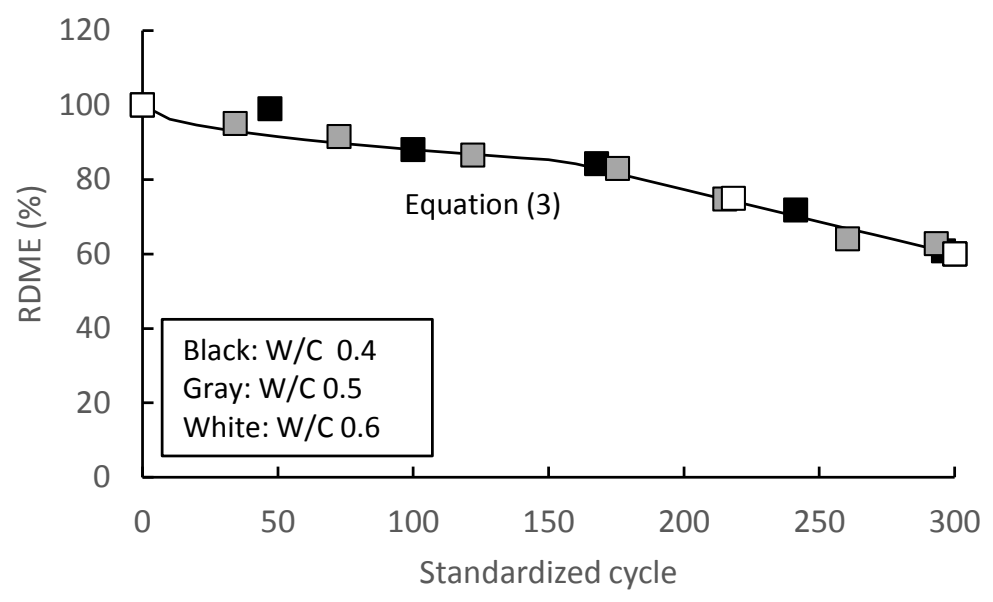

Figure 3. Results of Standardization of RDME (No Coating)

The original equation was based on 100 cycles for a standardized cycle. In this study, 300 cycles have been used for the standardized cycle. In this way, the decrease in the RDME can be expressed as a curve. A previous study has proposed the following equation to express the curve [Katsura 2003]:

$$
\begin{array}{ll}
\text { RDME }=-2.08(n / 3)^{0.5}+100 & (\text { RDME }>85 \%) \\
\text { RDME }=-0.520((n / 3)-51.9)+85 & (\text { RDME } \leq 85 \%)
\end{array}
$$

where $n$ is the standardized cycle number. The obtained curve is also shown in Figure 3. A high correlation between the measured value and the value estimated from equation (3) was observed.

Figure 4 shows an example of the standardized RDME of a specimen with a coating material (W/C 0.4, W-TN-E). It found that the RDME curve of the specimen was different from the RDME curve of the uncoated specimen as expressed by equation (3). It was observed that there was no decrease in the RDME in early cycles. It seemed that these cycles indicated the time taken to reach the critical saturation degree in coated concrete. The coating material prevented water absorption and delayed the time to reach the critical saturation degree. The decrease in the RDME after cycles in which there is no decrease in the RDME can be expressed by equation (3). From this, cycles $(\mathrm{Cp})$ in which deterioration was prevented by the coating material were identified; $\mathrm{Cp}$ is an indicator of the preventive effect of the coating material against frost damage. Figure 5 shows the results of the Cp calculation. In this study, an RDME of $97 \%$ was defined as the extent of Cp considering the RDME measurement error, and the standardized cycle at RDME 97\% was calculated. From Figure 5, no correlation between $\mathrm{Cp}$ and W/C was identified. It was found that $\mathrm{Cp}$ depended on the deterioration of the concrete because cracks in the concrete accelerated the deterioration of the coating material. 
Figure 6 shows the relationship between the vapor permeability and the average $\mathrm{Cp}$ value. A high correlation was observed. It seemed that in general the potential mass transfer of the coating material represented by the vapor permeability affected the $\mathrm{Cp}$ value.

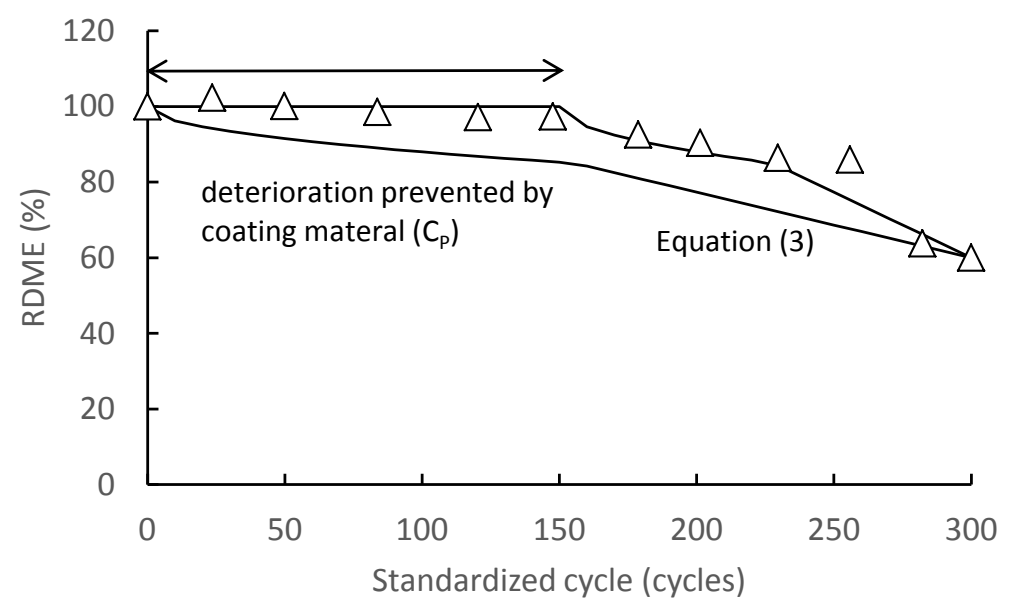

Figure 4. Example of Results of Standardization of RDME of Specimen with Coating Material (W-TN-E, W/C 0.4)

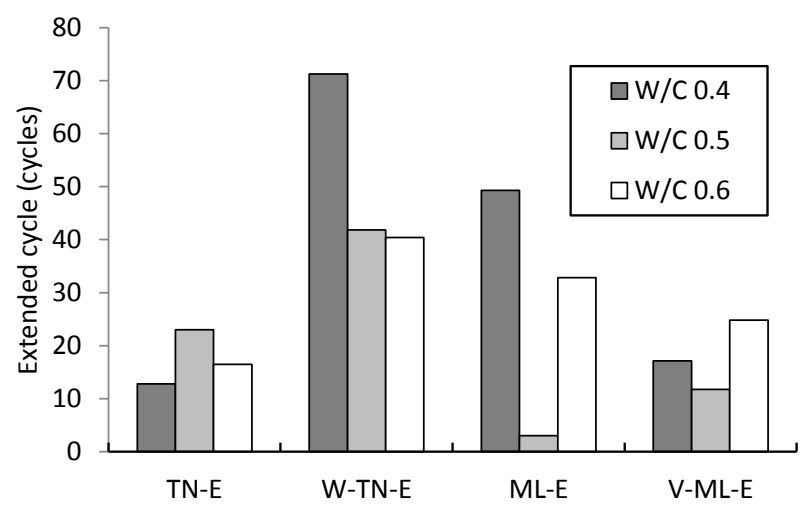

Figure 5. Results of Cp Calculation

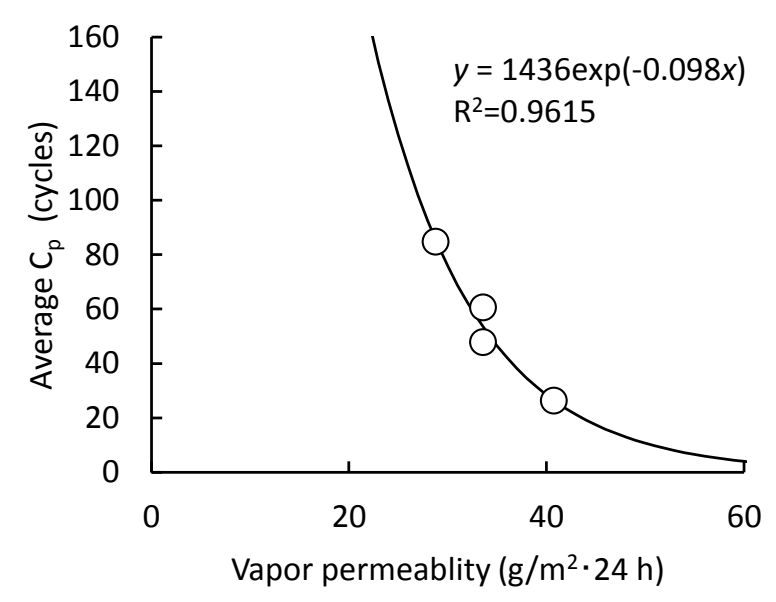

Figure 6. Relationship between Vapor Permeability and Average Cp 


\section{Outdoor exposure test results}

The outdoor exposure test results are shown in Figure 7 (outdoor exposure test 1) and Figure 8 (outdoor exposure test 2). In Figure 7, the dotted line indicates the strain change at an RDME of $60 \%$ obtained from Figure 2. According to both test results, none of the specimens were particularly deteriorated because non-AE concrete was used. It was observed that the deterioration of coated specimens was delayed in comparison with uncoated specimens.

An attempt was made to estimate the outdoor exposure test results using $\mathrm{Cp}$. The procedure is shown in Figure 9. It was assumed that the deterioration processes of concrete exposed to outdoor conditions and of accelerated freezing and thawing are the same. The RDME in outdoor exposure test 1 was obtained from the strain change using relationship in Figure 2. The standardized cycle was calculated using the RDME of uncoated specimens and equation (3). The value of $\mathrm{Cp}$ was estimated from the vapor permeability in Table 3 using the relationship in Figure 7. The RDMEs of coated specimens were estimated from the RDME of the uncoated specimen using the estimated $\mathrm{Cp}$ and equation (3). Figure 10 shows the relationship between the estimated and measured RDMEs. It may be possible to roughly estimate the outdoor exposure test results. These outdoor exposure test results show the early stage of deterioration. Data from more deteriorated concrete should be studied. The effect of deterioration of the coating material itself on $\mathrm{Cp}$ and the reason for the dispersion in Figure 5 needs further investigation.
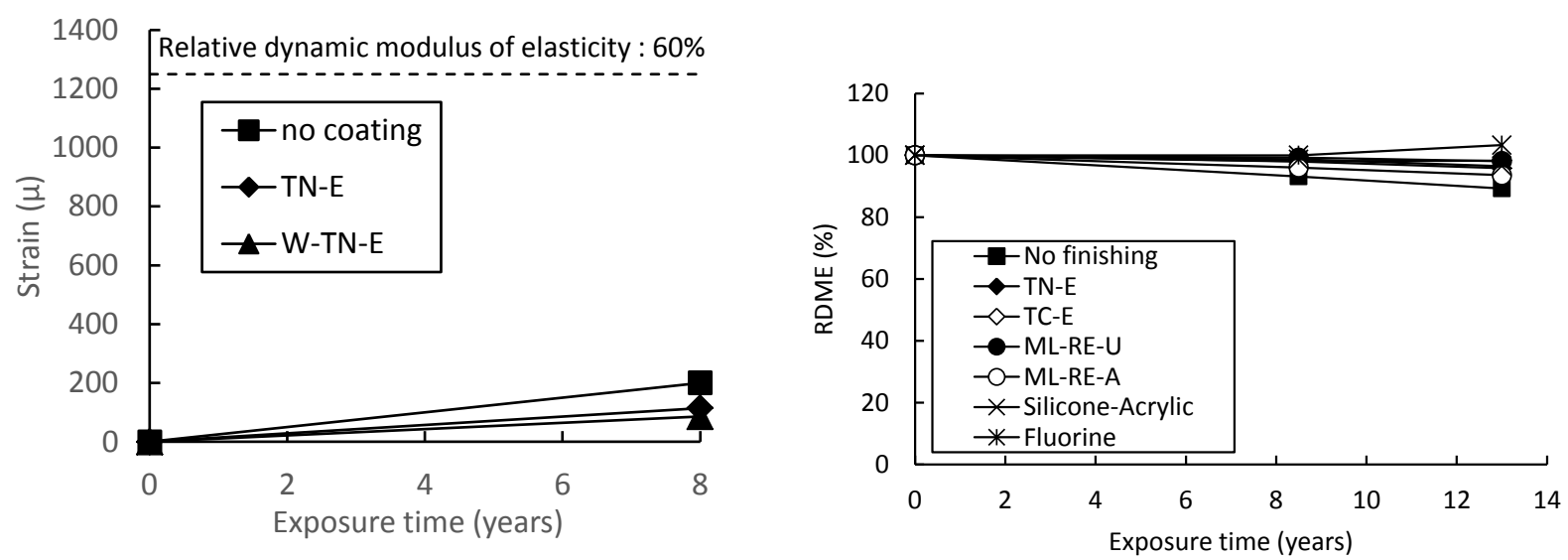

Figure 7. Results of Outdoor Exposure Test 1 Figure 8. Results of Outdoor Exposure Test 2
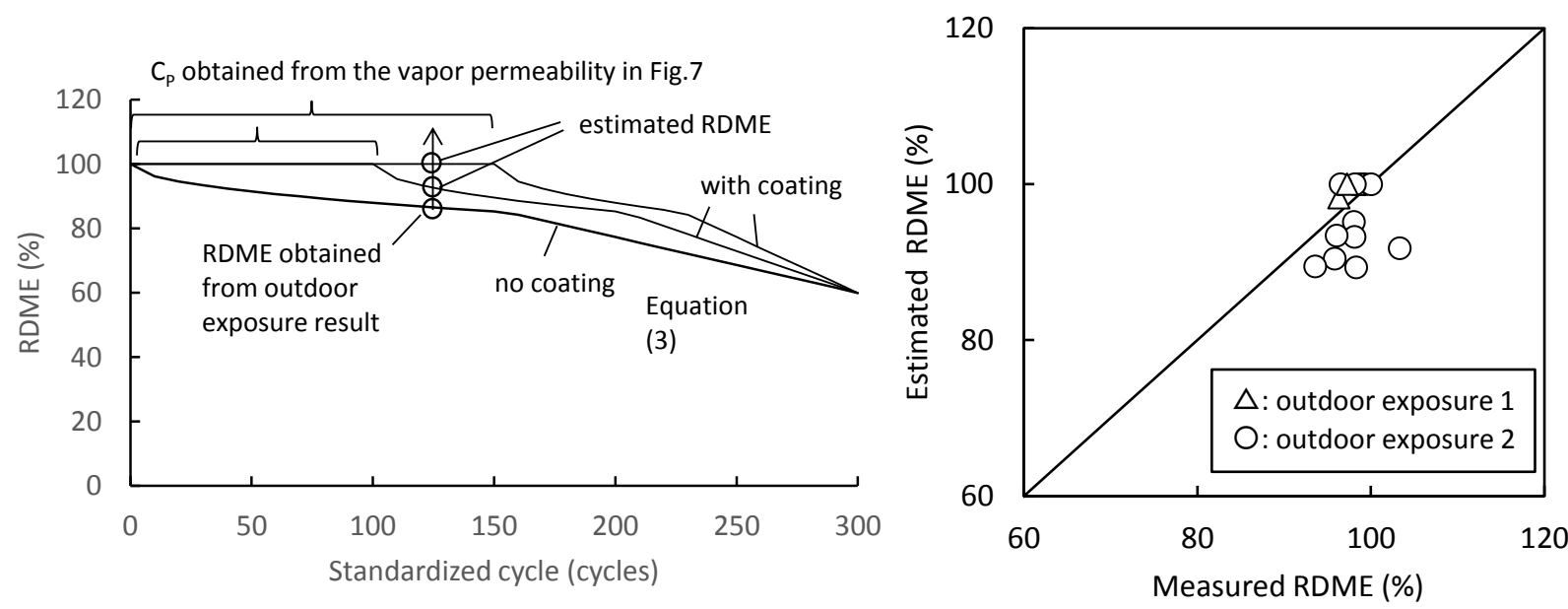

Figure 9. RDME Estimation Procedure

Figure 10. Relationship between Measured and Estimated RDME 


\section{CONCLUSION}

The conclusions can be summarized as follows.

- The preventive effects of coating materials against frost damage in concrete were confirmed. However, deterioration of concrete coated with a low-waterproof coating material may be accelerated in comparison with uncoated concrete.

- The decrease in the RDME in the accelerated freezing and thawing test can be expressed as a curve using standardized cycles. In the case of coated concrete, no decrease in the RDME in early cycles was observed. The decreasing RDME process after cycles in which there was no decrease in the RDME was the same as the process seen in uncoated concrete.

- A high correlation was observed between the vapor permeability of the coating material and the cycles in which there was no RDME decrease.

- A method of estimating the RDME decrease caused by frost damage in coated concrete was proposed. However, further investigation is needed to improve the accuracy of the estimation.

\section{ACKNOWLEDGEMENTS}

The authors sincerely thank the many students of Hokkaido University who helped with the experiments.

\section{REFERENCES}

Hasegawa, T., Ohkubo, T., Koga, J., and Senbu, O. (2006). "A prediction method of carbonation of concrete with finishing materials applied to the surface considering their vapor permeability." Proceedings of the 2 nd fib Congress, Naples, Italy.

Hasegawa, T., and Senbu, O. (2008). "A prediction method of carbonation in concrete with improved surface layer," Proceedings of Structural Faults + Repair-2008, Edinburgh, UK.

Katsura, O., and Matsumura, U. (2003). "Study on evaluation and estimation method of the extent of frost damage in concrete." Proceedings of symposium on testing method of concrete, AIJ, 2-11-16.

Sato, S., Hattori, K., and Ogata, H. (2000). "Nondestructive test methods or maintenance and management of agricultural hydraulic concrete structures." Proceedings of the XIV memorial CIGR world congress 2000, Tsukuba, Japan.

Shirota, T., Sakai, K., Sato, T., and Takahashi, J. (1997). "Control of frost damage to concrete by surface coating." Concrete research and technology, JCI, 8(1), 13-26. 